\title{
Laboratory Comparison of Aging Characteristics of Warm Mix Asphalts Involving Natural and Synthetic Water Containing Additives
}

\author{
Ali Topal ${ }^{a *}$, Peyman Aghazadeh Dokandari ${ }^{b}$ \\ ${ }^{a}$ Department of Civil Engineering, Faculty of Engineering, Dokuz Eylul University, \\ 35160, Buca, Izmir, Turkey \\ ${ }^{b}$ Graduate School of Natural and Applied Sciences, Dokuz Eylul University, 35160, Buca, Izmir, Turkey
}

Received: July 9, 2013; Revised: August 21, 2014

\begin{abstract}
When comparing the aging characteristics of hot and warm mix asphalts from a technical point of view, it can intuitively be expected that a warm mix asphalt would be less subjected to aging-induced failures due to lower application temperatures. Since the side effects of warm asphalt technology should be investigated distinctly. This study addresses the aging investigation of properties of bituminous mixtures containing two (i.e., natural and synthetic zeolite) water based additives available on the market. Within the scope of this study, short- and long-term aging conditions were simulated on mixtures containing various contents of additives as well as on control specimens. The aging indices were determined based on the hardness ratio employing indirect tensile strength values in order to investigate the aging induced failures betide by time. Aging indices showed that the specimens with water containing additives demonstrate relatively better resistance against hardening than conventional hot mix asphalt specimens.
\end{abstract}

Keywords: warm mix asphalt, water containing additive, natural zeolite, synthetic zeolite, aging

\section{Introduction}

Conventional Hot Mix Asphalt (HMA) covers the majority of the field pavement practices around the world. Since the human being has noticed changes in temperature of the atmosphere, concern about global warming issues has led the researchers to look for applications with lower temperatures. In addition to ecological issues, economic matters also were taken into account by lowering application temperatures. The less the application temperatures, the less fossil fuels is used to apply a bituminous layer. This issue is also important from the sustainable development point of view. In this regard, new technologies in pavement engineering was born. These new technologies are generally called Warm Mix Asphalt (WMA). Each WMA technology implements its unique way to reduce the application temperatures. WMA technologies generally can be categorized either by application temperature or by kind of process. Considering the application temperature, WMA technologies are classified by temperature reduction compared to HMA from half warm to cold mixes. On the other hand, the classification which takes the implemented technology into account separate WMA technologies mainly into two categories. The first category is based on the principle which is to introduce water into the mixture in order to cause foaming effect and the other one is based on the norm which is to modify bitumen by additives which are in potential of reducing the viscosity of the bitumen and consequently led to perform mixing and compaction at lower temperatures. Implementing of water in order to give bitumen foaming effects helping the aggregates be

*e-mail: ali.topal@deu.edu.tr coated with more facility has been found useful on this subject. Since some methods use direct injection of water in order to provide foaming effects some others have been developed to use different methods to provide the same effect. One of the successful methods of foaming WMA technologies is to implement substances which preserve a certain amount of water within its microstructure. Zeolites due to their honeycomb micro-structure can perform this fact in a perfect manner. When heated above the boiling point of water the moisture within zeolite micro pores is released, since the remaining material can play filler role inside the mixture. Zeolites used as WMA additives can be found in natural and synthetic forms. The zeolites supposed to be used as WMA additives must meet the required criteria such as encompassing a particular amount of water within their micro pores and not having side effects on bituminous mixture. Hereby the side effect means not changing the chemical structures of asphalt in an adverse manner as well as not having an unfavorable effect on mixture characteristics and performance of bituminous materials. The synthetic zeolite to be evaluated has been developed to meet these criteria since there are some kinds of natural zeolites in nature which can suit the required properties. Clinoptilolite is one of the most common zeolites found in powder form in the nature which meet the criteria for use in WMA. This study investigates the basic and lifetime properties of WMA mixtures containing both natural and synthetic zeolites looking for the capability of natural zeolite as an alternative additive for synthetic zeolite for use in WMA. 
Premature failures of asphalt pavements are often caused by diminishing of the binding forces in the mixture by the effect of moisture or mechanical stresses or aging of bitumen. These failures affect the service life of the pavement at high levels. It is important to predict the pavement behavior during its service life. The matter that how this behavior would be changed when using additives in different temperatures should be also taken into account seriously. The durability of asphalt concrete can be defined as a measure of its level of resistance to hardening (also called aging) over time ${ }^{1}$. Application temperatures have been found to be very important on the aging properties of bituminous mixtures. The effect of time and environmental factors on the aging of bitumen is a subject of continuous interest ${ }^{2}$. Earlier studies conducted on the effect of temperature and relative humidity on the oxidation of bitumen as a function of exposure time, showed that the rate of oxidation is dependent on both of these environmental factors ${ }^{3}$. The effect of ambient temperature on the aging characteristics of the bitumen is rather well documented. Petersen ${ }^{4}$ pointed out that three basic factors control the changes that would result in aging in bitumen. First factor better called volatilization is the loss of the oily components of bitumen by volatility or by absorption of porous aggregates. Second factor called oxidation is known as the change in the chemical composition of bitumen resulted from reaction with oxygen. Third factor known as steric hardening is molecular structuring that produces thixotropic effects. Among these factors, oxidation is mainly considered as a major contributing factor in the hardening of the asphalt pavement.

The literature review shows that aging of asphalt occurs in two terms called Short- and Long-term respectively ${ }^{5}$. Short-term aging occurs during mixing and final placement (construction phase) when the asphalt is at elevated temperatures. This can be caused by both oxidation and volatilization effects. Long-term aging occurs partially throughout the short-term aging frame and while the asphalt is in service and exposed to the environment. This longterm aging is predominantly caused by oxidation. Aging of asphalt may be influenced simultaneously by several factors, such as characteristics and content of the bitumen, nature and particle size distribution of the aggregates, void content of the mixture, production related factors, and external conditions such as temperature and time ${ }^{6}$. Asphalt additives would considerably change the mixture characteristics.
Beside the effect of modification in bitumen, lowering the application temperatures would positively affect the durability of asphalt concrete. It can intuitively be expected that a WMA pavement would be less subjected to aging than a HMA pavement in construction and hauling phases. This study attempts to evaluate the effects of natural and synthetic zeolites on aging characteristics of bituminous mixtures in terms of service life of flexible pavements.

\section{Experimental}

\subsection{Materials}

The bitumen used in this study was 50/70 penetration grade bitumen which was provided from TUPRAŞ, Izmir refinery. This grade of penetration is commonly used in Izmir due to climatic conditions. In order to characterize the properties of the base bitumen, conventional test results for base bitumen conducted at the Dokuz Eylul University (DEU), Highway Materials Laboratory are given in Table 1.

A mix of basalt and limestone aggregates provided from Dere Madencilik Inc. (Quarry located in Belkahve - Izmir) was used in this study. Physical properties of each kind are given in Table 2.

After conducting the associated tests based on ASTM C 136-06, a mix gradation of basalt and limestone is intentionally chosen to provide desired performance in conformity with Turkish specifications concerning the Type 1 wearing course. Basalt plays the role of strengthening constituent as coarse aggregate while limestone participates in the fine aggregate framework. The gradation is given in Table 3.

One of the well-known foaming WMA additives in the market is Advera ${ }^{\circledR}$ WMA a synthetic zeolite (Hydrated Aluminosilicate) developed by the PQ corporation in Malvern, Pennsylvania. It contains about $18 \%$ to $21 \%$ water of crystallization which has released by increasing temperature above the boiling point of the water. The expansion of water causes foaming of bitumen. The manufacturer of this type of synthetic zeolite proposes $4 \%$ to $6 \%$ use of this additive by weight of bitumen ${ }^{7}$. Introducing high amounts of water into bituminous mixtures can result in adhesion problems and a corresponding moisture induced damages ${ }^{8}$. In other respects, low water amounts will not be capable of producing adequate steam bubbles and consequently not leading to bitumen expansion and

Table 1. The properties of the base bitumen.

\begin{tabular}{llcc}
\hline \multicolumn{1}{c}{ Test } & \multicolumn{1}{c}{ Specification } & Results & Specification Limit \\
\hline Penetration $\left(25^{\circ} \mathrm{C} ; 0.1 \mathrm{~mm}\right)$ & ASTM D5-97 EN 1426 & 63 & 50 to 70 \\
Softening Point $\left({ }^{\circ} \mathrm{C}\right)$ & ASTM D36-95 EN 1427 & 49 & 46 to 54 \\
Viscosity at $\left(135^{\circ} \mathrm{C}\right)$, Pa.s & ASTM D4402-06 & 0.51 & - \\
Thin Film Oven Test (TFOT); $\left(163^{\circ} \mathrm{C} ; 5 \mathrm{hr}\right)$ & ASTM D1754-97 EN 12607-1 & & 0.07 \\
Change of Mass $(\%)$ & & 51 & 0.5 (max.) \\
Retained Penetration $(\%)$ & ASTM D5-05 EN 1426 & 51 & 50 (min.) \\
Softening Point after TFOT $\left({ }^{\circ} \mathrm{C}\right)$ & ASTM D36-95 EN 1427 & 100 & 48 (min.) \\
Ductility $\left(25^{\circ} \mathrm{C}\right), \mathrm{cm}$ & ASTM D113-07 & 1.030 & - \\
Specific Gravity & ASTM D70-03 & $260+$ & - \\
Flash Point $\left({ }^{\circ} \mathrm{C}\right)$ & ASTM D92-01 EN 22592 & 230 (min.) \\
\hline
\end{tabular}


lowering viscosity. On this basis, the required amount of water can be supplied by introducing $4 \%$ to $6 \%$ of zeolite. Implementing this synthetic zeolite in asphalt mixtures can reduce production temperature of about $10{ }^{\circ} \mathrm{C}$ to $30{ }^{\circ} \mathrm{C}^{[9]}$. Another recommended amount of use indicated in literature is $0.25 \%$ by total weight of the $\operatorname{mix}^{10}$. Advera ${ }^{\circledR}$ WMA contains about $18 \%$ to $21 \%$ water ${ }^{7}$.

Clinoptilolite was the natural zeolite used as the WMA water based additive within the scope of this study. Natural zeolite has been supplied from the a Turkish local company in powder form. The properties of natural zeolite are presented in Table 4.

Clinoptilolite can abundantly be found in Turkey. There are many quarries which contain plenty of this natural zeolite in powder form. It is much cheaper than synthetic zeolite and can potentially decrease the initial cost of WMA applications in significant manner. The powder form helps Clinoptilolite to enter the asphalt concrete structure after evolving its inherent moisture since it can easily pass the \#200 sieve. In fact, only an insignificant amount of filler enters into the gradation of the aggregates in this way which can be considered negligible.

During the studies at Highway Materials Laboratory, DEU; Clinoptilolite was found a suitable mineral to use in WMA mixtures. Laboratory tests showed that it can easily adsorb water by the amount of needed in WMA foaming technology (about 20\% by additive weight) and release steam bubbles at temperatures over the boiling point of

Table 2. The properties of the both basalt and limestone aggregates.

\begin{tabular}{lcccc}
\hline \multirow{2}{*}{ Test } & Specification & \multicolumn{2}{c}{ Types of Aggregate } & Specification Limit \\
& & Limestone & Basalt & \\
\hline Specific Gravity (Coarse Agg.) & ASTM C127-07 & & & \\
Bulk & & 2.686 & 2.666 & - \\
SSD & & 2.701 & 2.810 & - \\
Apparent & & 2.727 & 2.706 & - \\
Specific Gravity (Fine Agg.) & ASTM C128-07 & & & - \\
Bulk & & 2.687 & 2.652 & - \\
SSD & & 2.703 & 2.770 & - \\
Apparent & & 2.732 & 2.688 & max. 45 \\
Specific Gravity (Filler) & & 2.725 & 14.2 & max. 10 \\
Los Angeles Abrasion (\%) & ASTM C131-01 & 24.4 & 5.5 & max. 10 to 20 \\
Flat and Elongated Particles (\%) & ASTM D4791-10 & 7.5 & 2.6 & min. 40 \\
Sodium Sulfate Soundness (\%) & ASTM C88-05 & 1.47 & 58.1 & \\
Fine Aggregate Angularity & ASTM C1252-06 & 47.85 & & \\
\hline
\end{tabular}

Table 3. Gradation for basalt - limestone aggregate mixture.

\begin{tabular}{|c|c|c|c|c|c|c|}
\hline Test & $\begin{array}{c}19-12.5 \mathrm{~mm} \\
\text { (Basalt) }\end{array}$ & $\begin{array}{l}12.5-4.75 \mathrm{~mm} \\
\text { (Basalt) }\end{array}$ & $\begin{array}{c}4.75-0 \mathrm{~mm} \\
\text { (Limestone) }\end{array}$ & $\begin{array}{c}\text { Combined } \\
\text { Gradation (\%) }\end{array}$ & Spec. & Spec. Limit (\%) \\
\hline Mixture Ratio (\%) & 15 & 45 & 40 & & & \\
\hline Sieve Size $(\mathrm{mm})$ & & & & & ASTM C 136-06 & \\
\hline 19 & 100 & 100 & 100 & 100 & & 100 \\
\hline 12.5 & 35.7 & 100 & 100 & 90.5 & & $83-100$ \\
\hline 9.5 & 2.5 & 89 & 100 & 80.5 & & $70-90$ \\
\hline 4.75 & 0.4 & 16 & 100 & 47.3 & & $40-55$ \\
\hline 2 & 0.3 & 1.2 & 81 & 33 & & $25-38$ \\
\hline 0.425 & 0.2 & 0.7 & 33 & 13.5 & & $10-20$ \\
\hline 0.180 & 0.15 & 0.4 & 22 & 9 & & 6-15 \\
\hline 0.075 & 0.10 & 0.2 & 13 & 5.3 & & $4-10$ \\
\hline
\end{tabular}

Table 4. Physical properties and chemical structure of natural zeolite.

\begin{tabular}{|c|c|c|c|c|c|c|c|c|c|c|c|c|}
\hline \multicolumn{13}{|c|}{ Chemical Structure } \\
\hline & $\mathrm{SiO}_{2}$ & $\mathrm{Al}_{2} \mathrm{O}_{3}$ & $\mathrm{Fe}_{2} \mathrm{O}_{3}$ & $\mathrm{~K}_{2} \mathrm{O}$ & $\mathrm{H}_{2} \mathrm{O}$ & $\mathrm{CaO}$ & MgO & $\mathrm{Na}_{2} \mathrm{O}$ & $\mathbf{T i}$ & Ag & $\mathbf{N}$ & B (ppm) \\
\hline Content $(\%)$ & 71.29 & 13.55 & 1.15 & 3.5 & 5.9 & 1.96 & 0.7 & 0.6 & 0.02 & 0.04 & & 30 \\
\hline \multicolumn{13}{|c|}{ Physical Properties } \\
\hline Voids (\%) & $\begin{array}{l}\text { Dimensions } \\
\text { of the Main } \\
\text { Channels (A) }\end{array}$ & \multicolumn{3}{|c|}{ Thermal Stability } & \multicolumn{8}{|c|}{ Ion Exchange Capacity (meq/g) } \\
\hline 34 & $3.9 \times 5.4$ & \multicolumn{3}{|c|}{ High } & \multicolumn{8}{|c|}{2.16} \\
\hline
\end{tabular}


water. Release of tiny steam bubbles for a period of several hours can protract laying time with an improved workability. Laboratory experiments showed that it can highly preserve the moisture within its micro-pores when stored in bags.

\subsection{Experimental plan}

Based on the regarding modification temperature and mixing times for natural and synthetic zeolites, WMA bitumens were produced just before the mixing with aggregates process. Within the scope of this study, both natural and synthetic zeolites were added directly to the bitumen itself since it is possible to add the water based additive into the mixture. Although some studies say that adding zeolites directly to the bitumen will result in a more consistent mixture ${ }^{9}$, it is understood that actually the proper way of using zeolites as WMA additives is to add them directly into mixture during mixing phase in order to provide adequate expansion of bitumen. By the way, in laboratory conditions this would not provide the efficient expansion of asphalt due to bare amounts of mixtures. Accordingly, it was found effective to modify bitumen by zeolites in laboratory and immediately mix the modified bitumen with aggregates following the modification process. Modification temperature was supplied by a heater and controlled by a

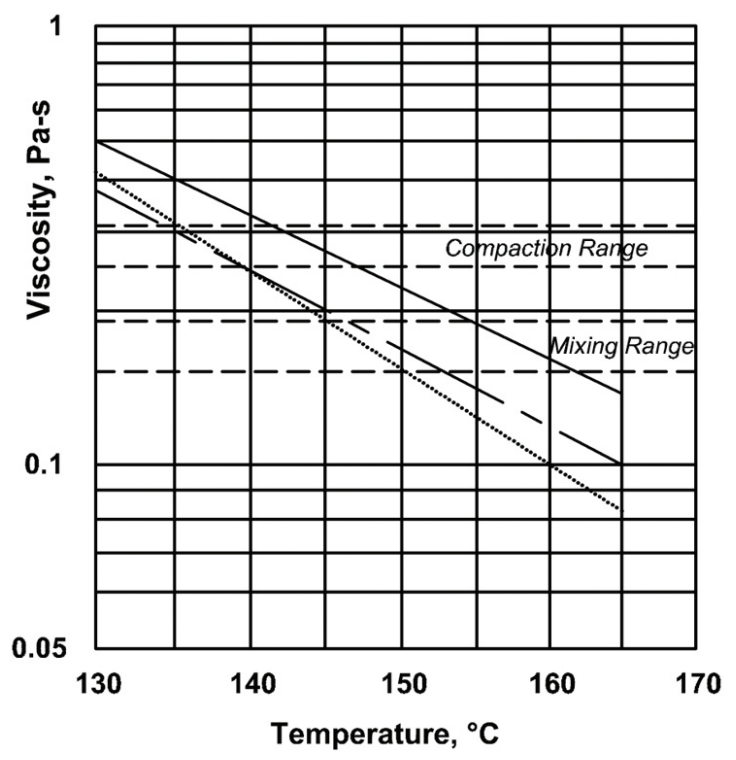

Base Bitumen

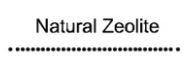

Synthetic Zeolite

Figure 1. Viscosity vs. temperature charts. digital industrial thermometer. An industrial stirrer was used in modification of WMA bitumens. Stirring was done in normal shear stresses since the modification of WMA bitumens doesn't demand for high shear stresses. Mixing temperatures and periods were determined based on trial and error method. In this method, after adding the specified amount of additive to the bitumen, stirring was started at the assigned temperature for a definite time period. After modification process, the viscosity of the new WMA bitumen was determined by a rotational viscometer. The procedure was repeated several times at a constant temperature for different time periods as well as at altered temperatures for a fixed time period. By tabulation of viscosity values under different temperatures and mixing periods, the border that the viscosity didn't change significantly was chosen as the optimum modification period and temperature. The optimum modification periods and temperatures are important values attributable to preserving bitumen from aging during the modification process. For both natural and synthetic zeolite modified bitumen, stirring for 20 minutes at $120^{\circ} \mathrm{C}$ temperature was determined as the optimum process.

Brookfield viscometer was employed to measure the viscosity of bitumen according to ASTM D4402-12. The test was performed at $135^{\circ} \mathrm{C}$ and $165^{\circ} \mathrm{C}$ respectively. After determining the viscosity values, mixing and compaction temperatures for the base and WMA bitumens were derived from viscosity - temperature charts in accordance with ASTM D2493-09. The experimental curves were plotted for base and additive containing bitumens. Curves for various bitumen types are presented in Figure 1. Acceptable equiviscous bitumen temperatures for mixing was chosen as the range corresponding to $0.17 \pm 0.02 \mathrm{~Pa}$.s and acceptable temperatures for compaction was chosen as the range matching $0.28 \pm 0.03$ Pa.s.

Mixing and compaction temperatures are given in Table 5. Data for base bitumen used in HMA is presented by $0 \%$ (no additive) in the table.

Following the production of natural and synthetic zeolite modified bitumens, WMA mixtures were prepared based on the determined mixing temperatures. The optimum bitumen content was determined by the Marshall mix design method. The optimum bitumen content for base bitumen, natural and synthetic zeolite modified bitumens were respectively determined as $4.76 \%, 4.56 \%$ and $4.32 \%$ by weight of the aggregates. The aggregates were placed in an oven adjusted for proper temperature the day before, to be completely dried and ready for mixing. Specimens were compacted with Marshall compactor regarding their compaction temperatures after mixing process. Conditioning

Table 5. Mixing and compaction temperatures.

\begin{tabular}{lccc}
\hline \multicolumn{1}{c}{ Additives } & Contents $(\%)$ & Mixing Temp. $\left({ }^{\circ} \mathbf{C}\right)$ & Compaction Temp. $\left({ }^{\circ} \mathbf{C}\right)$ \\
\hline Base Bitumen (AC 50/70) & 0 & $156-163$ & $143-149$ \\
Synthetic Zeolite & 4 & $152-159$ & $136-143$ \\
& 5 & $147-152$ & $135-140$ \\
& 6 & $158-165$ & $145-151$ \\
Natural Zeolite & 4 & $153-156$ & $139-142$ \\
& 5 & $146-150$ & $136-139$ \\
& 6 & $165-174$ & $145-154$ \\
\hline
\end{tabular}


as per AASHTO R 30 (2002) standard was done on the specimens intended to be aged. Short-term aged specimens were conditioned in a forced-draft oven set for $135^{\circ} \mathrm{C}$ for 4 hours and then compacted and cured since the long-term aged specimens were conditioned for 124 hours in a forceddraft oven set for $85^{\circ} \mathrm{C}$ after passing the short-term aging conditions. All processes regarding conditioning of the mixtures are shown in a flowchart in Figure 2.

All specimens were tested for Indirect Tensile Strength (ITS) after being cured. To perform this task, ASTM D6931-12 "The standard test method for indirect tensile strength of bituminous mixtures" was taken into account. The ITS test was conducted by the Marshall stability and flow apparatus. The loading rate was set to 51 $(\mathrm{mm} / \mathrm{min})$ in case for ITS. To be adequate and unbiased, three specimens for each additive content were prepared and tested randomly. The ITS results can give the evaluation keys in terms of low temperature and fatigue cracking of asphalt pavements. Studies introduce ITS result as a good indicator in predicting the laboratory rutting potential of asphalt mixtures ${ }^{11}$. This test is widely used in investigation of moisture induced damages of bituminous mixtures.

When evaluating the aging characteristics, as the bitumen ages, it becomes more brittle and stiffer, thus the ITS results of an aged mixture are rather more than the results of an un-aged specimen. Aging indices can be calculated based on this fact to investigate the aging characteristics of asphalt mixtures. Sengoz ${ }^{12}$ has implemented ITS results of mixtures to assess the effect of various air voids on aging and moisture susceptibility characteristics of HMA mixtures. Another study on short- and long-term aging behavior of rubber modified asphalts conducted by Liang and Lee ${ }^{13}$ has also proved the fact that short-term and long-term aging increases the measured tensile strengths. Sengoz and Topal ${ }^{14}$ investigated the effects of SBS polymer modified bitumen on the aging properties of asphalt mixtures using ITS results. They calculated aging indices as the ratio of short- and longterm aged specimen's ITS values to the values of un-aged control specimens prepared with the same additive content. Hurley and Prowell ${ }^{15}$ used ITS results to check the rutting potential after application and also short- and long-term aging characterization of WMA mixes containing Sasobit ${ }^{\circledR}$ (an organic WMA additive).

The raw data recorded from the test device should be processed using the following Equation 1 to obtain ITS values:

$\mathrm{S}_{\mathrm{t}}=(2000 \times \mathrm{P}) /(\pi \times \mathrm{t} \times \mathrm{D})$

Where:

$\mathrm{S}_{\mathrm{t}}=$ Indirect tensile strength (ITS), $\mathrm{kPa}$

$\mathrm{P}=$ Maximum load, $\mathrm{N}$

$\mathrm{t}=$ Specimen height immediately before test, $\mathrm{mm}$

$\mathrm{D}=$ Specimen diameter, $\mathrm{mm}$.

\section{Results and Discussions}

The results for temperatures corresponding to compaction and mixing ranges are given in Table 5. Considering the upper levels of temperature ranges, it is evident that the mixing and compaction temperatures are lowered respectively by $11^{\circ} \mathrm{C}$ and $9{ }^{\circ} \mathrm{C}$ (by the addition of $5 \%$ synthetic zeolite additive) and $13{ }^{\circ} \mathrm{C}$ and $10{ }^{\circ} \mathrm{C}$ (by the addition of $5 \%$ natural zeolite additive). The reduction in temperature as a result of using the natural zeolite was found more than using the synthetic zeolite. Natural zeolite can be used as an alternative WMA water based additive for synthetic zeolite additive. Studies show that zeolites improve various performance characteristics of bituminous mixtures

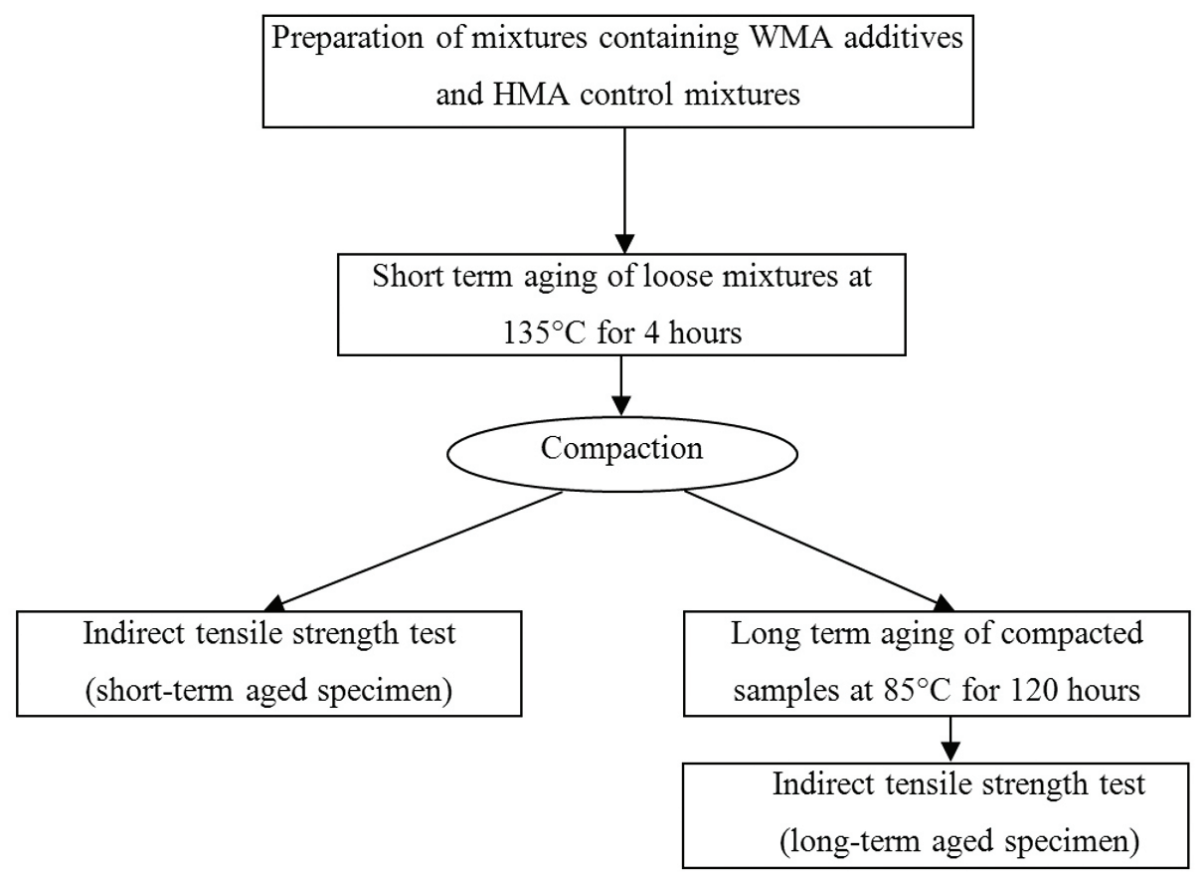

Figure 2. Short- and long-term conditioning flowchart. 
such as the repetitive loading strength and permanent deformation ability ${ }^{16}$.

The ITS results for un-aged, short- and long-term aged specimens are given in Figure 3 and Figure 4 for natural and synthetic zeolite modified specimens respectively. In these figures, additive content corresponding 0 simply demonstrates the HMA control specimens. The results of un-aged specimens indicate that using both natural and synthetic zeolite can soften the mixture according to the indirect tensile strength test results. Lower ITS values in case of un-aged specimens, can be explained by lower adhesion born of moisture remaining within the mixture.

According to the figures, the differences between the ITS values of un-aged and aged specimens slightly decrease by increasing in additive content. Aging indices can provide better evaluation for the effects of lower application temperatures on aging characteristics of bituminous mixtures. In this study, these indices were calculated as the ratio of ITS values of short- and long-term aged specimens over ITS values of HMA control specimens.

The calculating equations for the short-term aging index (SAI) and long-term aging index (LAI) are given in Equation 2 and Equation 3 respectively.

ITS (kPa) - Natural Zeolite Additive Content (\%)

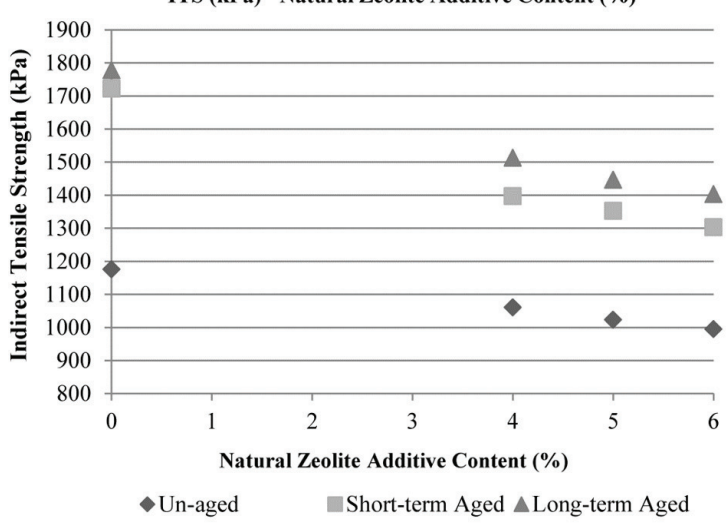

Figure 3. ITS results corresponding additive contents for natural zeolite modified mixtures.

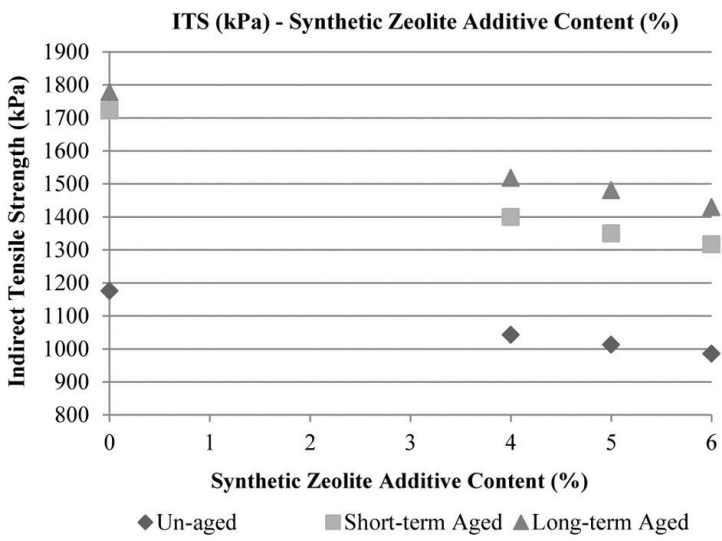

Figure 4. ITS results corresponding additive contents for synthetic zeolite modified mixtures.
$\mathrm{SAI}=(\mathrm{ITS}$ value of short-term aged specimen $) /$

(ITS value of un-aged specimen)

$\mathrm{LAI}=(\mathrm{ITS}$ value of long-term aged specimen $) /$ (ITS value of un-aged specimen)

By means of these indices, we are able to observe how hardened an aged specimen has become after the aging process. The less an aging index of a mixture is, the more resistive that mixture is against hardening. The SAI and LAI values for both natural and synthetic zeolite modified mixtures are demonstrated in Figure 5 and Figure 6 respectively.

As seen in the graphs, both natural and synthetic modified mixtures exhibited lower aging indices than control specimens. This can be explained by lower application temperatures. As discussed before, temperature is a vital factor in occasion of the aging. Lower application temperatures can cause less aging especially in case of shortterm aging. Having a glance on the slope of the trendlines for both SAI and LAI values, it can simply be realized that the drop in SAI values is more than the drop in LAI values. This can be clarified considering the effect of application
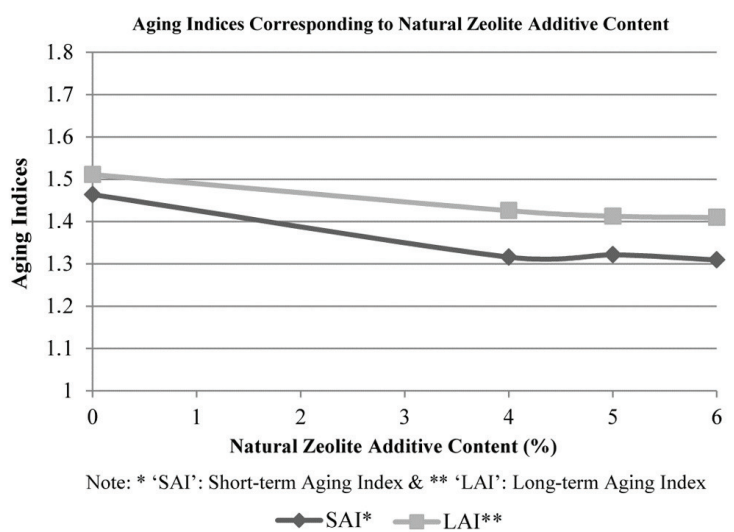

Figure 5. AI values corresponding to additive contents for natural zeolite modified mixtures.

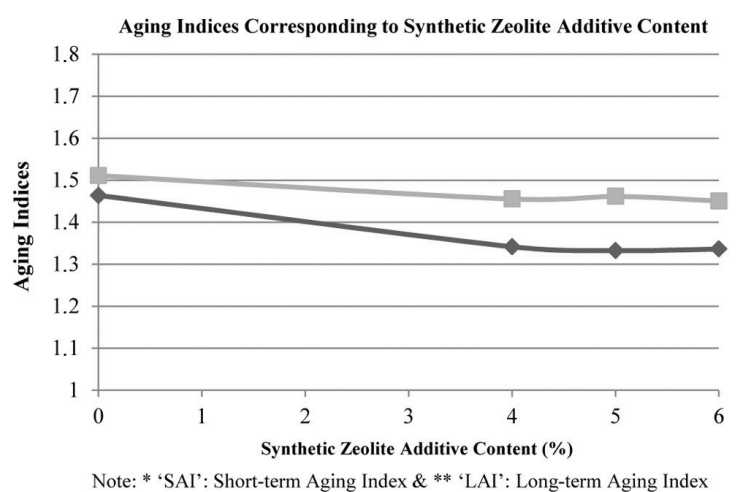

$\multimap \mathrm{SAI}^{*} \longrightarrow \mathrm{LAI} * *$

Figure 6. AI values corresponding to additive contents for synthetic zeolite modified mixtures. 
temperatures on aging of bituminous mixtures during the construction phase. The short-term aging occurs during production, storage and hauling at particular temperatures. These temperatures differ for WMA and HMA applications, since the long term conditions for both application types are mostly equal during the service life of the asphalt concretes.

Zeolite modified mixtures demonstrated better resistance against aging in comparison to HMA mixtures. Test results showed that increasing the additive content seemed not to have a considerable effect on aging indices. Hence it can be concluded that in the case of zeolites, rather than a micromechanical effect of zeolites on bitumen structure, it is the temperature which plays a vital role in lowering aging. Overall, even the long term aging remains at low levels compared to HMA specimens owing to the initial decrease in aging levels at short term aging phase.

\section{Conclusion}

Aging is not a defect by itself, but several pavement properties are influenced by the aging process. Among these properties, the properties of bitumen gained attention since the bitumen is aged; it becomes more susceptible to development of cracks and ravelling. It will be more sensitive to development of cracks due to rutting, low temperature, deformation and frost heave. With the development of WMA technology, these failures will eventually decrease due to lower mixing and compaction temperatures.

In the light of findings from experimental research it is possible to consider that synthetic and natural zeolite involving WMA exhibited better performance than conventional HMA based on the results gained from indirect tensile strength values. Besides, among the computed aging indices on short and long term aging processes the aging indices related to natural zeolite exhibited slightly better

\section{References}

1. Bell CA. Summary report on ageing of asphalt aggregate systems. Corvallis: Oregon State University; 1989. SR-OSUA-003A-89-2.

2. Campbell PG, Wrigth JR and Bowman PB. The effect of temperature and humidity on the oxidation of air blown asphalts. Materials Research Standards. 1962; 2(12):988-995.

3. Chipperfield EH. Asphalt characteristics in relation to road performance. Proceedings of Association of Asphalt Paving Technologists. 1970; 39:79-88.

4. Petersen JC. Chemical composition of asphalt as related to asphalt durability: state of art. Transportation Research Record. 1984; 999:13-30.

5. Bell CA, Wieder AJ and Felin MJ. Laboratory ageing of asphalt aggregate mixtures: field validation. Corvallis: Oregon State University; 1994. SHRP-A-390.

6. Xiaohu L and Isaccson U. Artificial ageing of polymer modified bitumens. Journal of Applied Polymer Science. 1999; 76(12):1811-1824.

7. Smith A. Advera ${ }^{\circledR}$ WMA zeolite. Hunt Valley: WMA Technical working group/PQ Corporation Presentation; 2011. Available from: <http://www.warmmixasphalt.com/ submissions/82_20080629_Annette_Smith_Advera_Caltrans. pdf>. Access in: 18/05/2011. performance than synthetic zeolite especially at higher rates of additives. It can therefore be concluded that natural zeolite can be used as an alternative WMA additive to synthetic zeolite. This puts forward the importance of using natural resources and taking the advantage of abundant natural zeolites existing around the shores of the Aegean Sea.

Since the WMA technologies are relatively new, the future research for these technologies include a wide area. Within the scope of this study, it was attempted to evaluate the aging phenomenon on bitumen-aggregate system. It is recommended that new researches include the investigation of aging on bitumen itself using alternative aging indices. These indices may be defined as the ratio of viscosity values or rheological properties of aged (by RTFOT and/or PAV) and un-aged bitumen samples involving WMA additives. Besides, further investigations should be carried out on microstructural properties of aged and un-aged bitumen samples involving WMA additives.

Utilization of WMA additives in lower temperatures is the dominating advantage of WMA technologies from the aging point of view. By using water containing WMA additives, obviously short term aging occurs less than conventional HMA pavements. Slightly replacements of HMA pavements with WMA pavements demand for updated specifications and application rules with new test procedures.

\section{Acknowledgments}

This research was sponsored by the Scientific and Technical Research Council of Turkey (TUBITAK) under the project number $110 \mathrm{M} 567$ for which the authors are greatly indebted. Besides, this study has been carried out with the valuable contribution of Dokuz Eylul University, The Graduate School of Natural and Applied Sciences.

8. Şengöz B, Topal A and Gorkem C. Evaluation of moisture characteristics of warm mix asphalt involving natural zeolite. Road Materials and Pavement Design. 2013; 14(4):933-945. http://dx.doi.org/10.1080/14680629.2013.817352.

9. D’Angelo J. Warm mix asphalt: European practice. Washington: Federal Highway Administration/Office of Policy/ Office of International Programs; 2008.

10. Rubio MC, Martinez G, Baena L and Moreno F. Warm mix asphalt: an overview. Journal of Cleaner Production. 2012; 24:76-84. http://dx.doi.org/10.1016/j.jclepro.2011.11.053.

11. Anderson RM, Christensen DW and Bonaquist R. Estimating the rutting potential of asphalt mixtures using superpave gyratory compaction properties and indirect tensile strength, (with discussion). Journal of the Association of Asphalt Paving Technologists. 2003; 72:1-26.

12. Sengoz B. The effect of asphalt film thickness on the ageing and moisture susceptibility of hot mix asphalt. [Dissertation]. Istanbul: Istanbul Technical University; 2003.

13. Liang RY and Lee S. Short-term and long-term ageing behavior of rubber modified asphalt paving mixture. Transportation Research Record. 1996; 1530(1):11-17. http://dx.doi. org/10.3141/1530-02.

14. Sengoz B and Topal A. Effect of SBS polymer modified bitumen on the ageing properties of asphalt. In: Proceedings of The 4th Eurasphalt and Eurobitume Congress; 2008; 
Copenhagen, Denmark. Copenhagen: EAPA; 2008. p. 11471153.

15. Hurley GC and Prowell BD. Evaluation of sasobit ${ }^{\circledR}$ for use in warm mix asphalt. Auburn: National Center for Asphalt Technology; 2005.
16. Topal A, Sengoz B, Kok BV, Yilmaz M, Aghazadeh Dokandari $\mathrm{P}$, Oner J, et al. Evaluation of mixture characteristics of warm mix asphalt involving natural and synthetic zeolite additives. Construction \& Building Materials. 2014; 57:38-44. http:// dx.doi.org/10.1016/j.conbuildmat.2014.01.093. 